\title{
Teaching probability: a socio-constructivist perspective
}

\author{
Sashi Sharma \\ The University of Waikato, Hamilton, New Zealand \\ e-mail: sashi@waikato.ac.nz
}

Summary

There is a considerable and rich literature on students' misconceptions in probability. However, less attention has been paid to the development of students' probabilistic thinking in the classroom. This paper offers a sequence, grounded in socio-constructivist perspective for teaching probability.

Keywords: $\quad$ Probability; Expected values; Modeling; Socio-constructivist; Teaching sequence; Statistical investigation.

'The excitement that a gambler feels when making a bet is equal to the amount he might win times the probability of winning it' (Blaisé Pascal, 1623-1662)

\section{INTRODUCTION}

Probability straddles a number of disciplines (physics, economics and sciences) because of its wide range of applicability. Moreover, the language of probability pervades almost everything we do. For example, probabilities of side effects of medication, risks of household accidents, environmental impact based on probabilistic calculations regularly appear in the news media and research reports (Olofsson 2010; Woolfson 2012). Gal (2005) suggests that attention to real-world demands should be part of the consideration that guide what becomes taught, assessed and valued in the statistics classroom.

Modelling in probability can provide the link between mathematics and aspects of the real world (Begg 1995; Greer and Mukhopadhyay 2005). Begg (1995) states that since modelling in statistics is carried out with pictorial and concrete material rather than with equations and graphs, it provides an ideal teaching platform for mathematical explorations.

In games of chance, a game is said to be fair if the price paid to enter the game is equal to the expected winnings. The gain or loss is the difference between the entry fee and the winnings. If the expected gain from the game is 0 , the game is fair. To answer a question such as this we need the concept of expected value.

Although examples such as below often appear in real life situations, expected values are taught procedurally at senior levels.

You're at a carnival and you see a game. For $\$ 2$ you roll a standard six-sided die. If the number showing is a six you win $\$ 10$, otherwise you win nothing.

Despite the importance of probability, a number of research studies (Amir and Williams 1999; Fischbein and Schnarch 1997; Jones et al. 2007; Lecoutre 1992; Sharma 1997; Watson 2006) from different theoretical perspectives show that students tend to have conceptions about probability which impact on their learning. For example, researches by Amir and Williams (1999) and Sharma (1997) show that a number of students think that their results depend on a force, beyond their control, which determines the eventual outcome of an event. Some pupils thought God controls everything that happens in the world while others thought God chooses to control. There were also beliefs directly related to coins and dice; for instance, when throwing a coin tail is luckier.

One explanation for above could be an emphasis in the classroom on procedural knowledge. Quite often in statistics students are capable of doing the calculations correctly (e.g. Bakker 2004; Ben-Zvi 2004; McGatha Cobb \& McClain 2002; Watson 2006) and yet many students have difficulty in understanding what the calculations mean, why these particular numbers are appropriate in a given context, and why seemingly 
suitable alternatives should be ignored on a particular occasion.

For deeper conceptual understanding learners need not only to have procedural knowledge including facts and procedures, but also to know how to relate them around big ideas and how to apply it in new situations (Bransford, Brown, \& Cocking, 1999).

Additionally, there are different viewpoints on how best to teach probability so that students leaving school may be able to interpret probabilities in a wide range of situations (Jones et al. 2007). These views are based on different interpretations of probability. People think about probability in at least three different ways (classical, frequentist and subjective) and these views can be manifested in the teaching and learning process. Each of these interpretations has its advantages and disadvantages (Batanero et al. 2005). If students are to develop meaningful understanding of probability, it is important to acknowledge these different interpretations and to explore the connections between them and the different contexts in which one or the other may be useful.

The classical (theoretical) viewpoint assumes that it is possible to represent the sample space (all possible outcomes) as a collection of outcomes with known probabilities. When the outcomes are equally likely, the probability can be found by counting the number of favourable outcomes and dividing by the total number of outcomes in the sample space. For example, the probability of rolling a six on a regular six-sided die is one-sixth. Additionally, one can examine the symmetry of a regular six-sided die and estimate the probability of rolling a six as one-sixth. In both cases, the theoretically derived probability is an estimate of the actual probability that is not known. Batanero et al. (2005) argue that although equiprobability may be clear when rolling a die or playing a chance game, it is not the same in complex everyday situations. Indeed equal chance can hardly be found in rare cases such as weather predictions, risks and sports. For example, Waikato plays netball against Auckland and can win, draw or lose by definition so $P$ (Auckland wins) is $1 / 3$ ( 1 favourable outcome, 3 possibilities). Furthermore, in some classroom situations, there is no theoretical probability. Indeed, when rolling an unfair die, the only way of estimating the actual probability of an event is to perform an experiment using a large number of trials (Groth 2007).

The frequency interpretation assumes that the probability of something happening can be determined by doing experiments. A large number of identical trials (e.g. tossing 2 coins) are conducted, and the number of times a particular event (e.g. $1 \mathrm{H}$ and $1 \mathrm{~T}$ ) occurs is counted. The greater the number of trials the closer the experimental probability will move towards the theoretical probability of an event. By comparing inferences from their theoretical and empirical work, students can evaluate and modify their hypotheses. From a practical interpretation, the frequentist approach does not provide the probability of an event when it is physically impossible to repeat an experiment a very large number of times. For example, there is no possibility of conducting repeated trials for estimating the probability that Mr Pua will live beyond 70 years or that Sharma's house will be burgled within a year. It is also difficult to decide how many trials are needed to have a good estimation for the probability of an event.

Different interpretations of probability are possible. However, such integration can confuse students. A pupil who is thinking about probability can be confused by a problem sheet where one question asks them the probability of rolling a six and the next question asks them the probability of a boy saying they like football based on a survey (frequency interpretation).

In order to understand the interpretations of probability and related concepts such as expected values, students need opportunities to develop their intuitions through empirical investigations that can motivate and help them construct sound understanding. In other words, students should be actively involved in rich hands-on experiments.

\section{SOCIAL CONSTRUCTIVISM}

From a constructivist perspective, learning is affected by the knowledge, contexts, beliefs and attitudes that learners bring to the classroom. When students learn, their previous knowledge does not go away, it becomes integrated with the new knowledge. (Garfield and Ben-Zvi 2009, p. 72). More specifically, social constructivism focuses on 'the development of "knowledge communities" as a larger unit of analysis provided it is connected to its effects on independent reasoning patterns for individual students, as also a target unit of analysis.' (Confrey and Kazak 2006, p. 319). For example, the approach taken by Yackel and Cobb (1996) reflects the view that mathematical learning is both a process of active individual construction and a process of acculturation into the mathematical practices of wider society. 
In the social constructivist tradition, social processes are important mechanisms through which participants negotiate meaning and co-construct knowledge in collaborative learning environments (Cobb 2007). This means that teachers need to create learning environments where learners are actively engaged in activities and discussions. Many scholars (e.g. Carpenter et al. 2001; Garfield and Ben-Zvi 2009; Wood 2001) argue from a social constructivist perspective for an instructional sequence that begins with the presentation of a meaningful task or problem and continues with an invitation to solve that problem in multiple ways, which leads to the sharing, justifying and discussing of those problem solving strategies in small or large group discourses. The roles assumed by teacher and student, as well as the environment, associated with this type of teaching are different from the traditional approach (Garfield and Ben-Zvi 2009). The role of the teacher is to guide learning in ways that are supported so that the students are able to achieve the desired outcomes. Teachers need to be aware of student prior knowledge and what knowledge students will be expected to construct and where this will ultimately lead.

A strategy that aligns with constructivist theories of learning and often used in science is Predict, Observe and Explain. It can be used in probability for finding out students' initial ideas; providing teachers with information about students' thinking; generating discussion and motivating students to want to explore the concepts (Joyce 2006). Events that surprise create conditions where students may be ready to start re-examining their personal theories. The strategy is based on the following principles:

- Unless students are asked to predict first what will happen, they may not observe carefully.

- Writing down their prediction motivates them to want to know the answer.

- Asking students to explain the reasons for their predictions gives the teacher indications of their theories. This can be useful for uncovering misconceptions or developing understandings they have.

- Explaining and evaluating their predictions and listening to others' predictions help students to begin evaluating their own learning and constructing new meanings.

The open-ended investigation described below is grounded in the social constructivist theory which could be used to introduce probability and expectation, particularly of functions of random variables. The game discussed can be investigated by high school, middle school and primary school students. The activity offers a meaningful context in which students can collect their own data and derive both experimental and theoretical solutions. Younger students can solve the problem intuitively and informally through experimental simulations whereas older students can delve into the problem and look for patterns that may help derive theoretical models. The sequence covers a range of criteria for a rich mathematical activity (Breyfogle and Williams 2008) and includes suggestions for adapting the activity.

\section{A POSSIBLE TEACHING SEQUENCE TO EXPLORE PROBABILITY AND RELATED CONCEPTS IN A DIE ROLLING GAME}

The phases involved in the teaching sequence resonate with Wild and Pfannkuch's (1999) statistical Problem, Plan, Data, Analysis, Conclusion (PPDAC) cycle mnemonic with slight modifications. After presenting a problem, the teacher could ask students to make predictions about the fairness of the dice rolling game.

Students are asked to make predictions about the fairness of a game and then test them by gathering and examining data. Students' predictions and conclusions are examined and re-examined in interactions with small group members, whole class and the teacher as he or she monitors small group work. Students need access to statistics software to produce graphs.

It induces students thinking about expected values. The expected value (mean) of a discrete probability distribution equals the sum of all the values $x$ each multiplied by the probability of $x$ occurring. Additionally, if samples are repeatedly taken from a population, then after time, an estimated mean of the values could be found. The mean of these values is called the expected value.

Specifically, the sequence examines the following:

- concepts of equally likely events, randomness, sample size, independence, probability distributions, variation (within a group and between distributions), organizing and displaying data, interpreting tables and graphs

- mathematical skills of basic facts, proportional reasoning, fractions

- mathematical practises with emphasis on reason abstractly and logically,

- construct viable arguments, critique the reasoning of others, making predictions and decisions, modelling, making connections, communicating statistically (verbally and in writing) 
The sequence is comprised of the following components:

\section{Posing a task}

Engage the students by posing a task that is set in a meaningful context. Ask the students to read through the die rolling task and make sure they understand it.

Esha and Sarah decide to play a die rolling game. They take turns to roll two fair dice and calculate the difference (larger number minus smaller number) of the showing numbers. If the difference score is 0,1 or 2, Esha wins, If the score is 3,4 or 5 , Sarah wins. Is this game fair? Explain your thinking.

Alternatively, the teacher could set this task a few days before the lesson and collect students' responses and examine what their work reveals about their current level of understanding. This will give the teacher an opportunity to find out the difficulties students have with it and be able to target help more effectively in the follow up lesson.

\section{Making predictions}

Individually, students think about whether the game is fair and write down their prediction and explanation in their books. Next, in pairs, students discuss their ideas and try to explain to each other why they chose the answers they did. At this stage, students could revise their predictions.

Circulate around and notice how students make a start on the task, whether they are drawing diagrams, working with probabilities or simply writing a description. As they work on the task, listen to their reasoning carefully and note misconceptions that arise for later discussion with the whole class.

Expected student responses: The probabilities are dependent on the rules of the game. Combining simple events such as tossing two dice and writing the difference usually creates a much more complex sample space than the original event. A single fair die has equiprobable outcomes whereas for the difference of two fair dice the outcomes are not equally likely. Students may think that symmetrical objects such as coins and dice always produce outcomes which are equally likely. This highlights the misconception that all outcomes are equally likely without considering that some are much more likely than others. Some students may think that some numbers are naturally luckier than others. If students do not believe that a six-sided die is fair, that is, has the same chance of coming up on each side, then discussion of the die rolling game considering fairness at the next level of complexity is likely to be challenging. You may have to provide further activity which encourages students to examine their ideas about the likelihood of events occurring before embarking to the next phase.

\section{Playing the game in pairs}

Pair students and have them play a round of the game described above. Explain that they are going to roll the two dice and calculate the difference of the numbers showing. With student feedback, list the possible outcomes $(0,1,2,3,4$ and 5) on board.

Students play the game about 20 times with a partner, and tally the results in a frequency table.

\begin{tabular}{lll}
\hline Outcome Tally & Frequency \\
\hline
\end{tabular}

Player A wins

Player B wins

Another possibility for a table is:

\begin{tabular}{lll}
\hline Roll number & A wins & B wins \\
\hline Total number of wins & \\
\hline
\end{tabular}

Based on the data, students record their responses to the following questions and then discuss these with another group. You may have to provide some sentence beginners to help students write their responses, for example, from the table it can be seen that....................... because

Focus questions

- On the basis of your results, do you think the game is fair? Why, or why not?

- If you wanted to win this game, which player would you choose to be? Explain your answer.

- If you played the game 30 more times, would the results be the same as or different from the first game? If they would be different, how?

- What does fair mean from probability perspective?

Expected student responses: Some students will notice that the game is not fair since one of the two players wins more times and so change their minds about the fairness of the game. Some of the As may say that they can see nothing wrong with the game. Tell them that they are going to play again but this time all As will be Bs and vice versa. Some students will almost certainly object to this suggestion. Some may physically examine 
the dice. Others will hold onto the belief that one number is just luckier than the others. Some might think that there are six possible scores and three have been assigned to each player hence the game is fair.

\section{Planning explorations}

Pose the following questions and brainstorm responses.

- Why does Esha win more often than Sarah?

- How can we determine if the game is fair by collecting more data?

- How can we record our results?

Record student responses on the board. The whole class shares and discusses the means by which they can carry out experiments to test their predictions.

These experiments could involve physical or computer simulations. There needs to be some discussion on how a die should be rolled, it is important that the students roll the dice in the same manner in each trial. Let the students to suggest how they will record their group results. One possibility is given below.

\begin{tabular}{lll}
\hline Outcome & $\begin{array}{c}\text { Frequency of } \\
\text { occurrence (tally) }\end{array}$ & $\begin{array}{c}\text { Relative frequency, or } \\
\text { experimental probability }\end{array}$ \\
\hline 0 & \\
1 & \\
2 & \\
3 & \\
4 & \\
5 & \\
Totals & \\
\hline
\end{tabular}

\section{Data collection and analysis}

In groups of three, data is collected and recorded. Next, group results are collated on the whiteboard and students analyse the pooled data (e.g. out of 180 trials).

\begin{tabular}{lccc}
\hline Outcome Total frequency & Probability & Estimated expectation \\
\hline 0 & (e.g. 26$)$ & $26 / 180=0.14$ & 25.2 \\
1 & & & \\
\hline
\end{tabular}

The expectation column is found by multiplying each probability by the total frequency (180).

Class results are compared with students' initial ideas and group data leading to the realization that Esha wins more often than Sarah. Have a discussion about the expected values being decimal numbers. This could lead into students investigating expected values for a random variable. If a fair die is rolled 1,000 times, we should be close to
166 sixes. We would not be surprised if we only obtained 160 because die rolling is a random process. However, if we obtained 100 sixes, there could be something wrong. In theory, we should have 166.66 sixes. They would realize that an expected value is a theoretical average or ideal result that should occur.

In groups, students answer the following questions. Alternatively, students can construct and present a poster to convince the rest of the class that they have made the appropriate decision. Students could use technology to produce graphs of data. The displays may resemble bar graphs or histograms since they can show the frequency of occurrences for each possible outcome.

From the results:

- What are the chances of Esha winning?

- What are the chances of Sarah winning?

- Is this game fair? Why?

- Draw a graph of the combined data. What patterns do you see in the graph?

- Why is this the best type of graph to use?

- How might this display look if we gathered more data?

\section{Further exploration}

In groups, students analyse the game to determine why Esha wins more often than Sara. Students need to enumerate the sample space in a systematic way. They can propose their own methods for listing the possibilities. Some possible approaches are listed below:

The outcomes can be listed and counted at the end.

\begin{tabular}{cccccc}
\hline $1-1$ & $1-2$ & $1-3$ & $1-4$ & $1-5$ & $1-6$ \\
\hline $2-1$ & $2-2$ & $2-3$ & & & \\
\hline
\end{tabular}

Note that 1-2 and 2-1 represent different dice outcomes but will give the same difference. One way to help students understand this is to use two dice of different colours.

Students could draw a table (figure 1) that sets out all possible scores (dice differences) and use it to find out the number of ways of obtaining each score (figure 2). The unbold numbers in the array are the differences of the numbers showing on the two dice. Listing all the outcomes in both methods reveals 36 possible combinations, 24 for Esha and 12 for Sarah.

The above differences can be combined together in the table in figure 2 to show the number of ways of obtaining each score. Figure 2 shows that 24 of the 36 equally likely outcomes 


DICE 1
\begin{tabular}{|l|l|l|l|l|l|l|l|}
\hline & & $\mathbf{1}$ & $\mathbf{2}$ & $\mathbf{3}$ & $\mathbf{4}$ & $\mathbf{5}$ & $\mathbf{6}$ \\
\cline { 2 - 9 } & $\mathbf{1}$ & 0 & 1 & 2 & 3 & 4 & 5 \\
\cline { 2 - 9 } & $\mathbf{2}$ & 1 & 0 & 1 & 2 & 3 & 4 \\
\cline { 2 - 9 } & $\mathbf{3}$ & 2 & 1 & 0 & 1 & 2 & 3 \\
\cline { 2 - 8 } & $\mathbf{4}$ & 3 & 2 & 1 & 0 & 1 & 2 \\
\cline { 2 - 8 } & $\mathbf{5}$ & 4 & 3 & 2 & 1 & 0 & 1 \\
\cline { 2 - 8 } & $\mathbf{6}$ & 5 & 4 & 3 & 2 & 1 & 0 \\
\hline
\end{tabular}

Fig. 1. Two-way table showing all possible differences

\begin{tabular}{|l|l|l|l|l|l|l|}
\hline $\begin{array}{l}\text { Difference } \\
\text { score }\end{array}$ & 0 & 1 & 2 & 3 & 4 & 5 \\
\hline $\begin{array}{l}\text { Number of } \\
\text { ways of } \\
\text { getting it }\end{array}$ & 6 & 10 & 8 & 6 & 4 & 2 \\
\hline Who wins? & Esha & Esha & Esha & Sarah & Sarah & Sarah \\
\hline
\end{tabular}

Fig. 2. Number of ways of obtaining each score

result in a win for Esha, and 12 result in a win for Sarah. If we play the game a large number of times, we can expect Esha to win twice as often as Sarah.

Alternatively, a tree diagram can be used to find the total possibilities although this would be a bit cumbersome.

Focus questions

- Discuss how knowing the expected probabilities help understand why the game is unfair.

- What is the expected frequency of (say) score of 4 if you roll the two dice 72 times and 144 times?

- How can we change the rules so that each player attains the same chance of winning?

- What would the distribution for a completely fair game look like? There are many different ways of devising a fair game. One is to say that $A$ wins if the difference is 0,2 or 4 and $B$ wins if it is 1,3 or 5 . Another is to say $A$ wins if the score is 1 or 2, otherwise $B$.

\section{CONCLUSION}

Probabilistic thinking can be developed slowly and systematically using carefully designed sequences of activities in appropriate learning environments, which challenge students to explore, conjecture, reflect on any discrepancies they observe, evaluate and explain their reasoning. However, it can be challenging to create a learning environment where students feel safe expressing their views. For more information and practical advice about managing discussions see Garfield and Ben-Zvi (2009) and McClain and Cobb (2001).

Expectation is a big idea in the activity discussed in this article. It can help students start thinking about expected values, $E[g(X)]$
$=\Sigma g(x) f(x)$ and mean (u) of a binomial distribution. The function $\mathrm{g}(\mathrm{x})$ maps the results (difference in numbers) onto win for Esha, win for Sarah. Perhaps approaching probability through expectation might make more intuitive sense to learners.

The teaching approach involving predictions and activities advocated in this article has become attractive with the availability of computers and graphics calculators in the classroom. These tools have added an important resource to simulations in probability and statistics with random number generators. Teachers should not expect one or two experiments to have a huge impact on student reasoning.

\section{REFERENCES}

Amir, G. and Williams, J. (1999). Cultural influences on children's probabilistic thinking. Journal of Mathematical Behavior, 18(10), 85-107.

Bakker, A. (2004). Reasoning about shape as a pattern in variability. Statistics Education Research Journal, 3(2), 64-83.

Batanero, C., Henry, M. and Parzysz, B. (2005). The nature of chance and probability. In: G.A. Jones (ed.) Exploring Probability in School: Challenges for Teaching and Learning, pp. 15-37. New York: Springer.

Begg, A. (1995). Statistics and the mathematical processes. Teaching Statistics, 17(2), 40-45.

Ben-Zvi, D. (2004). Reasoning about variability in comparing distributions. Statistics Education Research Journal, 3, 42-63.

Bransford, C.A., Brown, A.L., and Cocking, R.R., (eds.) (2000). How people learn: Brain, mind, 
experience, and school. Washington, D.C.: National Academy Press.

Breyfogle, L. and Williams, L. (2008). Designing and implementing worthwhile task. Teaching Children Mathematics, 15(5), 276-280.

Carpenter, T.P., Ansell, E. and Levi, L. (2001). An alternative conception of teaching for understanding: case studies of two first-grade mathematics classes. In: T. Wood, B. Nelson and J. Warfield (eds.) Beyond Classical Pedagogy, pp. 27-46. Mahwah, NJ: Lawrence Erlbaum Associates.

Cobb, P. (2007). Putting philosophy to work: coping with multiple theoretical perspectives. In: F.K. Lester (ed.) Second Handbook of Research on Mathematics Teaching and Learning, pp. 3-38. Charlotte, NC: Information Age.

Confrey, J. and Kazak, S. (2006). A thirty-year reflection on constructivism in mathematics education in PME. In A. Gutiérrez and P. Boero (eds.) Handbook of Research on the Psychology of Mathematics Education: Past, Present and Future, pp. 305-345. Rotterdam: Sense Publishers.

Fischbein, E. and Schnarch, D. (1997). The evolution with age of probabilistic, intuitively based misconceptions. Journal for Research in Mathematics Education 28, 96-105.

Gal, I. (2005). Towards "probability literacy" for all citizens: building blocks and instructional dilemmas. In: G.A. Jones (ed.) Exploring Probability in School: Challenges for Teaching and Learning, pp. 39-63. New York: Springer

Garfield, J.B. and Ben-Zvi, D. (2009). Helping students develop statistical reasoning: implementing a statistical reasoning learning environment. Teaching Statistics, 31(3), 72-77.

Greer, G. and Mukhopadhyay, S. (2005). Teaching and learning the mathematization of uncertainty: historical, cultural, social and political contexts. In: G.A. Jones (ed.) Exploring Probability in School: Challenges for Teaching and Learning, pp. 297-324. New York: Springer.

Groth, R.E. (2007). Reflections on a researchinspired lesson about the fairness of dice.
Mathematics Teaching in the Middle School, 13(4), 237-243.

Jones, G.A., Langrall, C.W. and Mooney, E.S. (2007). Research in probability: responding to classroom realities. In: F.K. Lester Jr (ed.) Second Handbook of Research on Mathematics Teaching and Learning, pp 909-955. Reston: The National Council of Teachers of Mathematics.

Joyce, C. (2006). Predict, observe, explain (POE). Retrieved 11 June 2014 from http://arb.nzcer. org.nz/strategies/poe.php

Lecoutre, M. (1992). Cognitive models and problem spaces in purely random situations. Educational Studies in Mathematics, 23, 557-568.

McClain, K. Cobb, P. (2001). Supporting students ability to reason about data. Educational Studies in Mathematics, 45(1-3), 103-129.

McGatha, M., Cobb, P. and McClain, K. (2002). An analysis of students' initial statistical understandings: Developing a conjenctured learning trajectory. Journal of Mathematical Behaviour, 21, 339-355.

Olofsson, P. (2010). Probabilities: The Little Numbers That Rule Our Lives. New Jersey: John Wiley and Sons.

Sharma, S. (1997). Statistical ideas of high school students: some findings from Fiji. Unpublished doctoral thesis. Waikato University, Hamilton, New Zealand.

Watson, J.M. (2006). Statistical Literacy at School: Growth and Goals. Mahwah, NJ: Lawrence Erlbaum.

Wild, C.J. and Pfannkuch, M. (1999). Statistical thinking in empirical enquiry (with discussion). International Statistical Review, 67(3), 223-265.

Wood, T. (2001). Teaching differently: creating opportunities for learning mathematics. Theory Into Practice, 40, 110-124.

Woolfson, M. (2012). Everyday Probability and Statistics: Health, Elections Gambling and War. London: Imperial College Press.

Yackel, E. and Cobb, P. (1996). Sociomathematical norms, argumentation, and autonomy in mathematics. Journal for Research in Mathematics Education, 27(4), 458-477. 